Transient formation of DNA strand breaks during the induced differentiation of a human promyelocytic leukaemic cell line, HL-60

Farzin Farzaneh ${ }^{1}$, Rosalind Meldrum ${ }^{2}$ and Sydney Shall ${ }^{2}$

${ }^{1}$ Molecular Genetics Unit, Department of Obstetrics and Gynaecology, King's College School of Medicine and Dentistry, Denmark Hill, London SE5 8RX and ${ }^{2}$ Laboratory of Cell and Molecular Biology, School of Biological Sciences, University of Sussex, Brighton BN1 9QC, UK

Received February 3, 1987; Revised and Accepted March 31, 1987

Abstract

During the induced differentiation of the human promyelocytic leukaemic cell line, HL-60, along the myelocytic lineage, DNA strand-breaks are formed. These breaks which are formed in the face of a proficient DNA repair mechanism, are only transiently maintained and subsequently become religated. The ligation of these breaks requires the activity of the nuclear adenosine diphosphoribosyl transferase (ADPRT). Inhibition of nuclear ADPRT, an enzyme totally dependent on the presence of DNA strand-breaks for its activity and required for efficient DNA repair in eukaryotic cells, blocks the religation of these breaks but not their formation. The inhibition of DNA strand ligation in the differentiating HL-60 cells results in loss of viability and cell death.

\title{
Introduction
}

The human promyelocytic leukaemic cell line, HL-60, can be induced to differentiate along the myelocytic lineage by a number of agents including dimethyl sulphoxide (DMSO) and retinoic acid (1). Several studies have demonstrated the formation of DNA strand-breaks during cellular differentiation in a number of different cell types. We have shown that during the in vitro differentiation of primary avian skeletal myoblasts, single-strand DNA breaks are formed in the genome (2). Singlestrand DNA breaks are also formed during the induced differentiation of murine erythroleukaemic cells $(3,4)$, and in the in vitro differentiation of normal human granulocyte-macrophage progenitor cells (CFU-gm) (6). Resting circulatory human lymphocytes contain DNA breaks which are ligated during mitogen stimulation (6-9). More recently weisinger et al, have demonstrated that a purified myeloid cell differentiation inducing protein (MGI-2), which is produced by the myeloid cells themselves, causes the formation of single-strand breaks in closed circular SV-40 DNA.

It has been demonstrated that the ligation of DNA strand breaks which are formed curing myoblast differentiation or the ligation of DNA 
breaks present in resting lymphocytes, following the mitogenic activation of these cells, both require the activity of nuclear adenosine diphosphoribosyl transferase, ADPRT (11). The nuclear ADPRT, which is totally dependent on the presence of DNA strand-breaks for its activity (12), is involved in a variety of cellular processes which require the ligation of DNA strand-breaks, possibly because it regulates DNA ligase activity $(13,14)$. These processes include DNA excision repair (15), a number of examples of eukaryotic cellular differentiation $(2,5,15-19)$, mitogenic activation of quiescent lymphocytes (6-9), sister chromatid exchange $(20,21)$, antigenic variation in Trypanosoma brucei (22), and the stable expression of transfected DNA in mammalian host cells (24). For a recent review of ADPRT involvement in cellular processes see references 25 to 28.

In this study we have employed a sensitive nucleoid sedimentation technique to investigate the formation of DNA strand-breaks during the myelocytic differentiation of HL-60 cells induced by either DMSO (29), or retinoic acid (30). Inhibition of ADPRT activity by its competitive inhibitor 3-methoxybenzamide (31), does not affect the formation of these DNA strand breaks but does block their religation. Inhibition of ADPRT activity in the differentiating $\mathrm{HL}-60$ cells results in cell death.

\section{Materials and Mothods}

\section{Cells and culture Conditions}

The human promyelocytic cell line, $\mathrm{HL}-60$ (in passage 25) was obtained from Dr Ming-Chi Wu, Biochemistry Department, North Texas State University. Cells were maintained at $1-10 \times 10^{5} \mathrm{cells} / \mathrm{ml}$ in RPMI 1640 medium supplemented with $10 \%(\mathrm{v} / \mathrm{v})$ foetal calf serum. Cultures were incubated at $37^{\circ} \mathrm{C}$ in tissue culture bottles, initially equilibrated in an atmosphere of $95 \%$ air $/ 5 \% \infty_{2}$. Routinely, cells were used in passages 30 to 40. For the induction of differentiation along the myelocytic lineage, cells in logarithmic growth (generation time approximately 32 hours) were adjusted to $2 \times 10^{5}$ cells $/ \mathrm{ml}$ and either DMsO or retinoic acid were added to a final concentration of $1.25 \%(\mathrm{v} / \mathrm{v})$ or $1 \mu \mathrm{M}$ respectively. Differentiation was then monitored at the indicated times by, a) the morphological appearance of cytospin preparations stained with May-Grunwald-Giemsa, b) the ability to recuce nitro-blue tetrazolium and c) phagocytosis of opsonised latex particles.

May-Grumwald-Giemsa staining:

Air-dried slides of cells were prepared using a cytocentrifuge at $1000 \mathrm{rpm}$ for five minutes. The slides were fixed in methanol for 20 
minutes and then stained for 5 minutes in 508 ( $/ / v)$ May-Grumwald stain followed by 30 minutes in Giemsa stain. Both stain solutions were freshly made using $10 \mathrm{mM}$ phosphate buffer, pH 7.0. After staining, the slides were washed and destained for 5 minutes in the phosphate buffer.

Nitro-blue-tetrazolium reduction:

Nitro-blue tetrazolium (NBT) recuction was estimated essentially as described by Ferrero et al, (32). Briefly, $0.2 \mathrm{ml}$ of a cell suspension containing $2 \times 10^{5}$ cells was incubated at $37^{\circ} \mathrm{C}$ for 30 minutes with $0.2 \mathrm{ml}$ NBT solution ( $2 \mathrm{mg} / \mathrm{ml}$ ) in calcium/magnesium-free phosphate-buffered saline containing $1 \mu \mathrm{g} / \mathrm{ml}$ of 12-0-tetradecanoylphorbol-13-acetate (TPA). At the end of the incubation period, the cells were collected on microscope slides using a cytocentrifuge as described above. Air-dried slides were fixed in methanol for 10 minutes and then stained in $1 \%(w / v)$ Saffranin 0.

Assay of phagocytosis:

Polystyrene latex particles $(0.81 \mu \mathrm{m}$ in diameter, Sigma) were opsonised with the human complement component $\mathrm{C3b}$, as described by Roberts (33). Briefly, latex particles in suspension, $10 \%(\mathrm{v} / \mathrm{v})$ in Kreb's Ringer phosphate, were incubated with an equal volume of fresh human serum for 30 minutes at $37^{\circ} \mathrm{C}$. The particles were then centrifuged for 2 minutes at $8000 \mathrm{~g}$, washed in $2 \mathrm{M} \mathrm{NaCl}$ to remove the adhered immunoglobulins and finally resuspended in Kreb's Ringer phosphate at a density of $10^{10}$ particles/ml. To assay for phagocytosis, $10^{6}$ cells resuspended in $0.5 \mathrm{ml}$ of serum-free RPMI 1640 medium were mixed with $10 \mu l$ of opsonised latex particle suspension and incubated at $37^{\circ} \mathrm{C}$ in an atmosphere of $58 \mathrm{co}_{2} / 958$ air, for 4 hours. Cells were then washed three times with Kreb's Ringer phosphate and collected by centrifugation at $500 \mathrm{~g}$ for 5 minutes. Cytospin slides stained with May-Grunwald-Giemsa were inspected by light microscopy. Cells containing 5 or more latex particles were scored as phagocytic.

\section{Nucleoid sedimentation:}

DNA strand break formation and rejoining was monitored by a modification of the previously described nucleold sedimentation technique (11) which was originally developed by cook et al (34). $2 \times 10^{6}$ cells in $50 \mu 1$ phosphate buffered saline containing $10 \mathrm{mM}$ EDTA was added to $500 \mu \mathrm{l}$ of the lysis solution $(2.0 \mathrm{M} \mathrm{NaCl}, 10 \mathrm{mM}$ EDTA, $127 \mu \mathrm{M}[50 \mu \mathrm{g} / \mathrm{ml}]$ ethidium bramide, $100 \mathrm{mM}$ Tris.HCl pH 8.0, 0.58 (v/v) Tritan-X-100), which was overlaid on $14 \mathrm{ml}$ of a 15-308 (w/v) linear sucrose gradient containing $2.0 \mathrm{M} \mathrm{NaCl}, 1.0 \mathrm{mM}$ EDTA, $127 \mu \mathrm{M}$ ethidium bramide, $10 \mathrm{mM}$ Tris.HCl, pH 8.0. This high concentration of ethidium becomide was included in the lysis and 


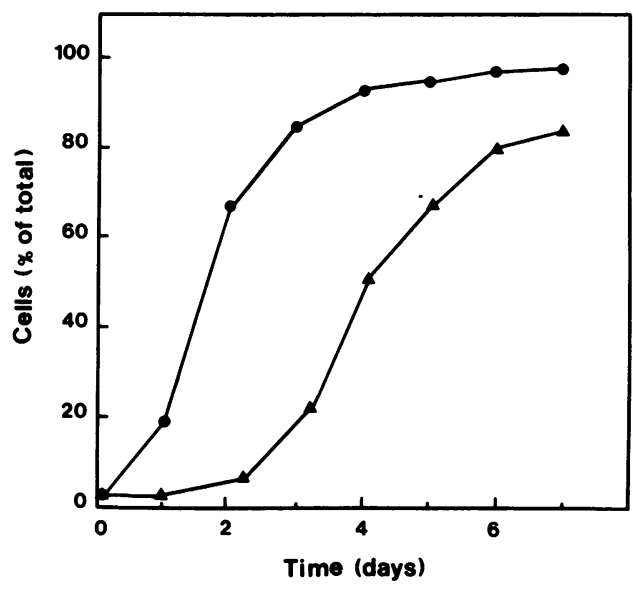

Fig. 1. DMSO-induced differentiation of HL-60 cells.

Nitro-blue-tetrazolium reduction ( $($ ); and phagocytosis of opsonised latex particles $(\boldsymbol{\Delta})$. Essentially similair results are obtained by the retinoic acid-induced differentiation of $\mathrm{HL}-60$ cells.

gradient solutions in order to avoid interference from changes in the superhelical structure of DNA and to enable simple visualisation of the position of the nucleoid band in the gradients. The gradients were kept in the dark, at room temperature, for 30 minutes and then centrifuged at 20000 rpm in a Beckman SW27.1 rotor for 1 hour. The positions of the nucleoid bands were visualised with an ultraviolet transilluminator and photographed with a polaroid camera fitted with a wratten 25 filter.

\section{Rosults}

HL-60 cells can be induced to differentiate along the myeloid lineage by either $1.25 \%(\mathrm{v} / \mathrm{v})$ DMSO or $1 \mu \mathrm{M}$ retinoic acid (Fig. 1). The induction of differentiation by either agent is first detectable at 24 hours when approximately $20 \%$ of the cells are capable of reducing nitro-blue-tetrazolium. After 5 days in culture, approximately $90 \%$ of the cells can reduce nitro-blue-tetrazolium. The induction of the ability to phagocytose latex particles takes langer and is first detectable after three days, reaching its maximum after 7 days when approximately $80 \%$ of the cells can phagocytose opsanised latex particles.

During the induced differentiation of $\mathrm{HL}-60$ cells alang the myelocytic lineage, DNA strand-breaks are formed. This is reflected in a reduction in the sedimentation rate of nucleoids during the first 24 hours 


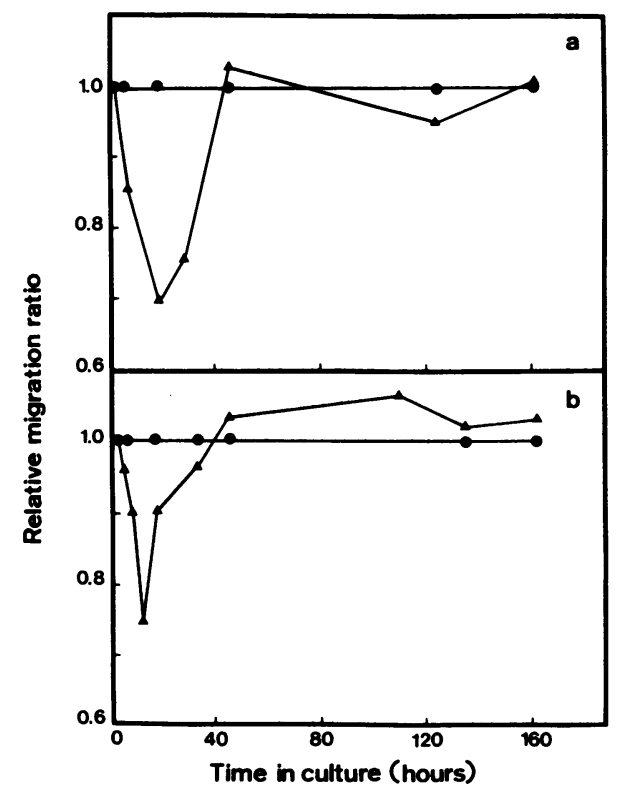

Fig. 2. Estimation of DNA strand-break fommation by nucleoid sedimentation analysis during myeolcytic differentiation of HI-60 cells.

Nucleoid sedimentation rate was measured at the indicated times in $\mathrm{HL}-60$ cells induced to differentiate ( $\Delta$ ) by either $1.25 \%(\mathrm{v} / \mathrm{v})$ DMSO (a), or $1 \mu \mathrm{M}$ retinolc acid (b). Results are expressed as a fraction of sedimentation rate in control, uninduced, HL-60 cells ( $O$ ).

of treatment with either DMSO (Fig. 2a) or retinoic acid (Fig. 2b), as compared to the sedimentation rate of nucleoids from parallel uninduced cultures. At this time very few cells are capable of reducing nitro-blue-tetrazolium which is ane of the earliest markers of differentiation in these cells (Fig. 1). The DNA breaks thus formed are only transiently maintained and are religated curing the subsequent 24 hours (Fig. 2).

Inhibition of ADPRT activity, by $2 \mathrm{mM} 3$-methoxybenzamide at $2 \mathrm{mM}$, blocks the religation of the DNA strand breaks which appear during differentiation, but it does not block their formation (Fig. 3a). In the DMSO-treated cultures in which ADPRT activity is blocked, the DNA strand-breaks do form, but in contrast to the uninhibited cultures, the DNA strand-breaks remain unligated during the subsequent period of incubation. This inhibition of DNA strand ligation is only observed with 3-methoxybenzamide, an enzyme inhibitor, and not with 3-methoxybenzoic acid, which 


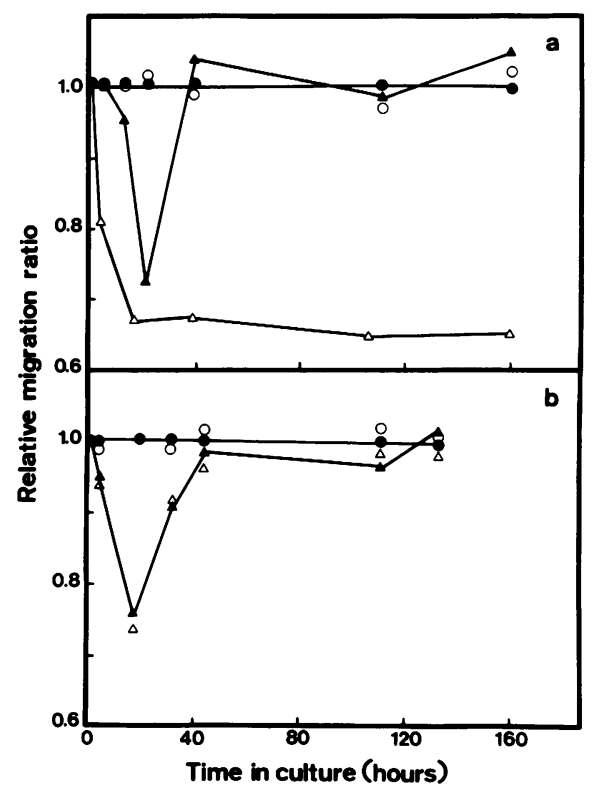

Fig.3. Effect of inhibition of ADPRT activity on DNA strand break fommation and re-ligation during HL-60 differentiation.

Nucleoid sedimentation rate in DMSO induced $\mathrm{HL}-60$ cells in the absence of an inhibitor ( $\Delta$ ); or in the presence of either $2 \mathrm{mM}$ 3-methoxybenzamide $(a, \Delta)$, or $2 \mathrm{mM} 3$-methoxybenzoic acid $(b, \Delta)$. Control cultures were either un-induced, HL-60 cells (O), or cells cultured in the presence of $2 \mathrm{mM}$ 3-methoxybenzamide $(a, O)$ or $2 \mathrm{mM} 3$-methoxybenzoic acid $(b, O)$. Results are expressed as a fraction of sedimentation rate in control, un-induced, HL-60 cells.

is not an inhibitor of ADPRT activity, (Fig. 3b). Neither $2 \mathrm{mM}$ 3-methoxybenzamide nor $2 \mathrm{mM}$ 3-methoxybenzoic acid have any detectable effect on the sedimentation rate of nucleoids in the uninduced control cultures. At the $2 \mathrm{mM}$ concentration used here neither compound has any effect on the cloning efficiency of control uninduced $\mathrm{HL}-60$ cells in soft agar (umpublished results), or the viability of these cells in culture (35), clearly demonstrating that 3-methoxybenzamide is not causing non-specific metabolic perturbations. Induction of differentiation by DMSO decreases the rate of cell growth in culture because the differentiated cells do not divide; again we see that $2 \mathrm{mM}$ 3-methoxybenzamide by itself does not affect the rate of cell growth. In contrast, in cultures induced to differentiate by $1.25 \%$ DMSO, exposure to 3-methoxybenzamide results in a dramatic reduction in cell growth and/or viability as judged by the number of trypan blue impermeable cells in culture (Fig. 4). 


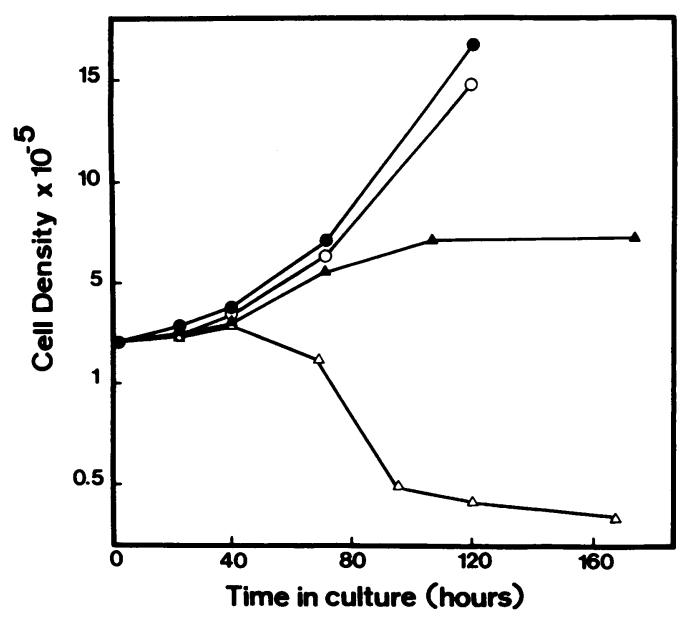

Fig.4. Effect of inhibition of ADPRT activity on cell density in control and differentiating cultures of HL-60 cells.

Cell density (trypan blue impermeable) was measured at the indicated times in control $\mathrm{HL}-60$ cells not exposed to an inducer (O); or cultured in the presence of only $1.25 \%(\mathrm{v} / \mathrm{v})$ DMSO $(\Delta)$; or in the presence of $2 \mathrm{mM}$

3-methoxybenzamide alone ( $O$ ); or in the combined presence of both $1.25 \%$

$(\mathrm{v} / \mathrm{v})$ DMSO and $2 \mathrm{mM}$ 3-methoxybenzamide $(\Delta)$.

\section{Discussion}

During the cellular differentiation of HL-60 cells alang the myelocytic lineage, induced by either DMSO or retinoic acid, DNA strand-breaks are formed. These breaks transiently accumulate early in the course of differentiation and are subsequently religated. The accumulation of these physiologically-formed DNA strand-breaks occurs despite the proficlency of differentiating $\mathrm{HL}-60$ cells in DNA repair (35). We have shown that DNA strand-breaks which are formed by either $\gamma$-irradiation or exposure of the $\mathrm{HL}-60$ cells to the monofunctional methylating agent (dimethylsulphate) are as proficiently repaired in the differentiating or differentiated $\mathrm{HL}-60$ cells as they are in the undifferentiated control cultures (please see the adjoining paper 35 ). It seems that the ligation of the DNA strand breaks which are formed by either ionising radiation or by exposure to monofunctional methylating agents as well as the physiologically-formed DNA strand breaks require nuclear ADPRT activity. The requirement for ADPRT activity has also been shown for the ligation of DNA strand-breaks which are present in the genome of resting lymphocytes, following their mitogenic activation (6-9). The inhibition of ADPRT 
activity in control, undifferentiated $\mathrm{HL}-60$ cells by $2 \mathrm{mM} 3$-methoxybenzamide, has no detectable effect on their viability or the more rigorous test of their cloning efficiency in semi-solid agar cultures.

In contrast to a previous report by Grosso and Pitot (36) we failed to detect any evidence of HL-60 differentiation by the inhibition of ADPRT activity at inhibitor concentrations which are not toxic to these cells. Therefore, the reported induction of differentiation by Grosso and Pitot may be a function of the cytotoxic property of these inhibitors at the unusually high concentrations (10 mM 3-aminobenzamide) used in their study (36).

In contrast to the undifferentiated cultures, the inhibition of ADPRT activity in the differentiating culture does result in cell death and loss of growth potential, possibly because the ligation of their DNA strand breaks is blocked. Of course, even in the absence of ADPRT inhibition, the differentiating cells do eventually become post mitotic and cultures cease to grow. However, in the ADPRT inhibited cultures the growth arrest is much earlier and in contrast to the nomal differentiating cultures there is actual cell death, as indicated by a substantial decrease in the number of viable cells.

In conclusion, the studies reported here demonstrate the transient formation of DNA strand-breaks during the induced myelocytic differentiation of $\mathrm{HL}-60$ cells in culture and that the subsequent ligation of these breaks requires nuclear ADPRT activity. Although DNA strand break formation has now been reported in a number of examples of cellular differentiation (2-9), their biological significance remains obscure. Perhaps the formation of DNA strand-breaks are required for alterations in gene expression necessary for cellular differentiation, possibly by regional chromatin relaxation of previously supercoiled domains in the genome. This notion is strengthened by the recent demonstration that a purified myeloid cell differentiation-incucing protein causes the formation of single-strand breaks in supercoiled SV-40 DNA (10).

\section{Adnowledgements}

This work was supported by grants from the Medical Research Council, Cancer Research Campaign and the London University Central Research Fund. We are grateful to Professors Stuart Campbell and William P. Collins for their support and encouragement in the course of this work. 


\section{References}

1. Abraham, J. and Rovera, J. (1981) in Handbook of Experimental Pharmacology, ed. Baserga, R. (Springer, Berlin), Vol. 57, pp 405-425.

2. Farzaneh, F., Zalin, R., Brill, D. and Shall, S. (1982) Nature 300, 362-366.

3. Terada, M., Nudel, U., Fibach, E., Rifkind, R.A. and Marks, P.A. (1978) Cancer Res. 38, 835-840.

4. Scher, W. and Friend, C. (1978) Cancer Res. 38, 841-849.

5. Francis, G.E., Gray, D.A., Berney, J.J., Wing, M.A., Guimarase, J.E.T. and Hoffbrand, A.V. (1983) Blood 62, 1055-1062.

6. Johnstone, A.P. and Williams, G.T. (1982) Nature 300, 368-370.

7. Greer, W. L. and Kaplan, J.G. (1983) Biochem. Biophys. Res. Commun. 115: 834-840.

8. Johnstane, A.P. (1984) Eur. J. Biochem. 140, 401-406.

9. Johnstone, A.P. and Darling, D. (1985) Immunology 55, 685-692.

10. Weisinger, G., Korn, A.P. and Sachs, L. (1986) FEBS Letters 200, 107-110.

11. Farzaneh, F., Shall, S. and Johnstone, A.P. (1985) FEBS Letters $189,62-66$.

12. Benjamin, R.G. and Gill, D.M. (1980) J. Biol. Chem. 255, 10493-10501.

13. Creissen, D. and Shall, S. (1982) Nature 296, 271-272.

14. Ohasi, Y., Ueda, K., Kawaichi, M. and Hayaishi, O. (1983) Proc. Natl. Acad. Sci. USA 80, 3604-3607.

15. Durkacz, B.W., Omidiji, O., Gray, D.A. and Shall, S. (1980) Nature 283, 593-596.

16. Althaus, F.R., Lawrence, S.D., He, Y.Z. Sattler, G.L., Tsukadar, Y. and Pitot, H.C. (1982) Nature 300, 366-368.

17. Williams, G.T. (1983) Exptl. Parasitology 56, 409-415.

18. Williams, G.T. (1984) J. Cell. Biol. 99, 79-82.

19. Francis, G.E., Ho, A.D., Gray, D.A, Berney, J.J., Wing,M.A., Yaxley, J.J., Ma, D.D.F. and Hoffbrand, A.V. (1984) Leukaemia Res. 8, 407-415.

20. Natarajan, A.J., Czukas, I., Degrassi, F., van Zeeland, A.A., Palitti, F., Tanzarella, C., De Salvia, R. and Fiore, M. (1982) Prog. Mut. Res. 4, 47-59.

21. Lindahl-Kiessling, K. and Shall, S. (1986) submitted to Carcinogenesis

22. Farzaneh, F., Shall, S., Michels, P., and Borst, P. (1985) Mol. Biochem. Parasitol. 14, 251-259.

23. Cornelissen, A.W.C.A., Michels, P.A.M., Borst, P., Spanyer, W., Versluiys-Broers, J.A.M., van der Meer, C., Farzaneh, F., and Shall, S. (1985) Biochem. Pharmacol. 34, 4151-4156.

24. Farzaneh, F., Linskens, M.H.K., Panayotou, G.N., Bowler, L.D., Broom, T. and Shall, S. (1987) Manuscript in preparation.

25. Ueda, K. and Hayaishi, O. (1985) Annu. Rev. Biochem. 54, 78-100.

26. Gaal, J.C. and Pearson, C. K. (1985) Biochem J. 230, 1-18.

27. Gaal, J.C. and Pearson, C.K. (1986) Trends in Biochemical Sciences 11, 171-175.

28. Althaus, F.R., Hilz, H. and Shall, S. (1985) eds. ADP-Ribosylation of Proteins, (Springer-Verlag, Berlin) pp 578.

29. Collins, S.J., Ruscetti, F.W., Gallagher, R.E. and Gallo, R.C. (1978). Proc. Natl. Acad. Sci. USA. 75, 2458-2462.

30. Breitman, T.R., Soolnik, S.E. and Collins, S.I. (1980). Proc. Natl. Acad. SCi. USA. 77, 2936-2940.

31. Purnell, M.R. and Whish, W.J.D. (1980) Biochem. J. 185, 775-777. 
32. Ferrero, D., Pessano, S., Pagliardi, C.L. and Rovera, G. (1983) 61, 171-179.

33. Roberts, P. (1983) Ph.D. Thesis University of London.

34. Cook, P.E., Brazell, I.A. and Jost, E. (1976) J. Cell Sci. 22, 303-324.

35. Farzaneh, F., Feon, S., Lebby, R.A., Brill, D., David, J.C. and Shall, S. (1987) Nucleic Acids Research, 15, 3503-3513.

36. Grosso, L.E. and Pitot, H.C. (1984) Biochem. Biophys. Res. Commun. 119, 473-480. 